\title{
Numerical and Experimental Predication of the Structural Cracking Within Reinforced Concrete Structure due to Conventional State of Loading
}

\author{
Hussam Ali Mohammed ${ }^{1}$, Hussein Abad Gazi Jaaz ${ }^{2}$, Ali Fadhil Naser ${ }^{*}$, Ayad Ali Mohammed ${ }^{1}$ \\ ${ }^{1}$ Al-Furat Al-Awsat Technical University, Al-Mussaib Technical College, Babylon City 51006, Iraq \\ ${ }^{2}$ Al-Furat Al-Awsat Technical University, Kufa City 54003, Iraq
}

Corresponding Author Email: com.ali3@atu.edu.iq

https://doi.org/10.18280/ijsse.110506

Received: 11 July 2021

Accepted: 26 September 2021

\section{Keywords:}

experimental, numerical, cracking, reinforced concrete, building, ANSYS, finite element

\begin{abstract}
It has been well understanding that the occurrence of various crack patterns in the building during its construction life (from first time of construction up to finishing) then subjected to super imposed load or during the service life. Cracks developed due to exceeding of stresses more than the allowable strength, wherever happened on building component. This research works used the finite element method as a powerful tool to simulate the behavior of full constructed building with both concrete system and brick bearing wall. Where the adopted numerical procedure allows to the users to predict the response of building elements due to conventional state of loading. one of the most important response features was the cracking phenomenon, where the numerical model shown that its capability to predict the cracking sequence from the first time of initiating. The prediction of full response and behavior of each element and their connection, shown that the precise of factor of safety used by the designer, where the analysis prove that the design load was about $67 \%$ from the cracking load, and the ultimate load was about $260 \%$ from the design load. That will allow more sustainability and stability for long time deformation. Beside the numerical solution, there was an experimental part of study, where site investigation, it shown that all data recorded was constant values and the building was stable. Actually, with no increasing of loading, the building reach its stable state, and defect will not develop. That basically because of good design within conventional state of loading.
\end{abstract}

\section{INTRODUCTION}

Civil structure must be accurately designed according to the cultural, social, and physical requests of the populations, and to provide a safe structure to protect them from the dangers that may influence from their environment actions. A safe structure must be founded on a strong foundation. Structural damages of foundations because of unsuitable design will lead to develop un-uniform settlement, cracks of walls and floor, and structural weakness. Methodical and technical development directed to the improvement of analysis and design methods of civil structures. Therefore, the stages of analysis developed simple and protect many times to definite the elastic and plastic performance in the structures well $[1,2]$.

The selection of building structural systems is one of the significant stages in the structural design of building. There are several concrete structural systems used in erection of buildings. Building structural systems are applied to factored loads and they shall be investigated to determine the internal forces such as axial loads, shear loads, stresses, moments, torsions, and deflections. Therefore, the building which consists of six stories can be analyzed as a space frame by adopting computer engineering software. Generally, the building structure can be met the conditions of stability, equilibrium, strength, aesthetics, and economical. The designer of buildings must be taken the economic state in the construction as possible. According to above it is important to mentioned that the principle of economic is important factor which is provided in the construction of building [3, 4].

The project of building structure is typically distributed for three stages. These stages include the design, erection and maintenance. The objective of these stages is to provide controlling documents. The design stage can be divided for the primary assessing and the design of building. The building procedure includes the tender for the erection works, the contracts and the quality investigation. Work structural performance is being received and the building is continued according to the instructions. There are some options can be presented how the members and experts are included in the project of building. These options are erection, creation planning and site engineering. Any building consists of some elements which are including natural soil layer, foundation, floor, wall, ceiling, frame, stairs, roof, windows, doors and furniture. The structural esign contains optional frame results, load determinations, foundations design, building components, roof structures and specifications with other collaborators. Building can be constructed in situ by using different construction materials such as concrete, timber, brick, and steel frame [5].

There are two main principles should be contented in the structural design of buildings. These principles include Ultimate Limit State (ULS) and Serviceability Limit State (SLS). Ultimate Limit State deals with the strength of the structural members of building to confirm the structural safety. Whereas, Serviceability Limit State concerns on the cracks widths which they are a significant factor for a reinforced 
concrete structure. Therefore, this principle deals with functionality and durability of structure. There is additional steel reinforcement necessity can be added to control the cracks when the results of damage inspection and cracks width determination of a concrete structure are more than max. allowable width of crack. A significant feature of the design and erection standards for concrete structures is to ensure enough service life of the structure $[6,7]$.

Cracks in different types are an important factor of reinforced concrete building. These cracks are un-uniformly distributed and also they have different widths and lengths along the structural member. On condition that the crack widths stay within an allowable value, these cracks will lead to reduce the serviceability and bearing capacity of the structure. The maximum crack width in the reinforced concrete part is importance and it is observable that visual appearance and durability of the reinforced concrete parts are most of all adversely effected by the maximum crack width. In structural design, the restriction of the crack width is completed by submitting with design guidelines and limitation of the maximum crack width under the critical load combination. However, the prediction of the maximum crack width of the reinforced concrete parts is not inconsequential and it has been much contested over the past decades [8-11].

Buildings and engineering constructions must not only meet the requirements of safety about their members of structures, but also must be had safe for their users. As a result of using of wrongdoings at the stages of building design, building will suffer from some damages and failure may be occurred According to the theoretical and experimental analyses which is carried out by the engineer, it was found that the most predominant reasons for the appearance of dangers, failures, and construction tragedies were the mistakes made by the members on all stages of the erection method and also by unexpected accidental influences. Damaged buildings that have been subjected to reinforcement or repair work may be permitted for exploitation $[12,13]$.

In structural design of building structural members, deflections and cracks regulator at service load levels are typically main observations. Therefore, it can be explained that why suitable model of concrete stiffness after cracking is required. Many stages of structures have been stated that were in obedience with ultimate limit states requirements, but were still influenced by excessive deflection or cracking. In several of these stages, failure due to creep and shrinkage at the design stage was established to be the main cause for such damages $[14,15]$.

The strength of concrete reinforcement importantly be influenced by the suitability of the connection between the steel reinforcement and concrete. Connecting is produced by adhesion and frictional conflict between the steel-concrete boundary. The strength of reinforced concrete mainly be influenced by environmental situations [16].

Generally, Modern building structures for a several decays up to nowadays used reinforced concrete as the main building materials. Because its look like an artificial stone that consider as the main frame on the structure, that could be obtained easily mixing cement, sand, and aggregates with water. As its being known that fresh concrete can be cast into almost any required shape and outline on the structures, giving it a natural benefit over other materials. The invention of Portland cement in the 19th century made concrete so popular overall the world, even of its limited tension resistance, that restrict it use in building construction. That on its role, lead to developed the concrete materials by handling his poor tensile strength by embedded steel bars within the concrete Skelton to get a composite material called reinforced concrete. Within the wide availability of its ingredients - reinforcing steel as well as concrete, lead to use the $\mathrm{RC}$ construction in the modern world stems. In addition to that, the production of concrete does not need expensive manufacturing factory. Also, the concrete construction does need a certain level of expertise, technology, and workmanship, mostly in the field during construction. That assist to construct a large number of singlefamily houses or low-rise residential buildings across the world using RC without any engineering assistance. But, within special cases, like seismic areas, a powerful design needed to be carefully done by specialist and whom have enough expertise.

Herein in this study, a practical case study is chosen to investigate the cracks predicted from conventional state of loading and a model constructed by numerical software to simulate the full behavior of overall reinforced concrete chosen building. Then a recommendation presented on the method for adopting numerical model to predict cracking on each building before construction. Nonlinearity came from cracking and crushing deal with and studied with the effects of the distributed loads on the performance of these systems. In the experimental part, monitoring of the cracks developed in this chosen building where located in Al-Mussaib Technical College. This research takes about six months monitoring, the cracks width measured by microscope.

\section{REVIEW OF EXISTING LITERATURE}

From researches reviewing, several research works carried out on analysis or/and design overall building with full details for its main structure elements. From the first was the analysis and design of $\mathrm{G}+5$ story residential building carried out by Naga and Lingeshwaran [17], that included analysis/design various members like beams, slabs, columns and foundation. Loads were calculated as per IS875/1987 (Fe415 are used as per IS 1986-1985 for both dead and live loads). His research study reveals that first architectural and structural design configuration of the whole building will provide the safety required. Also, higher quality of the structural analysis and design will lead to achieve stability of elements and their ductile performance.

Another $\mathrm{G}+5$ story building was analyzed and designed by Krishna and Chandrashekar [18], by using structural analysis and design software ETABS. Effect of lateral loading caused by wind and earthquake was considered in his study and its relevant data analysis is done by using ETABS. Furthermore, He consider more factors like chances of happening of spread of fire, with his try to follow the available standards to provide fire materials within his design. In his final recommendation, found that ETABS software is very advanced, original, and easier for high rise buildings, that could reduce designing process time.

After that, same software program ETABS was used to analysis and design $\mathrm{G}+13$ story residential building by Balaji and Selvarasan [19]. In this time, they consider static and dynamic loading conditions, especially earthquake. Liner analysis for both static and dynamic were carried out for all material properties. For more severe seismic zones, the author considers non-linear analysis, and the behavior was evaluated by considering type II soil condition. This research study 
predicts a displacements charts and variation of shear in the bases, and all plotted figures was studied.

Furthermore, ETABS software, another well-developed structural software program called STAAD was used. Vijaya and Madhu [20] published out a comparative study included analysis and design of multi storied building. Also, an additional details and information of both residential and commercial building design were provided in this research study. They plan with accordance of national building code and drafted using Auto CAD software. On general from this study, the STAAD revels conservative results of bending moment and axial force when compare to ETABS software.

Additional information on paper subject to review could be founded in references such as Ozer et al. [21], Baisbay et al. [22], Pina [23], Chandrakala et al. [24], Nagaratna et al. [25], Mahmood and Mohammad [26].

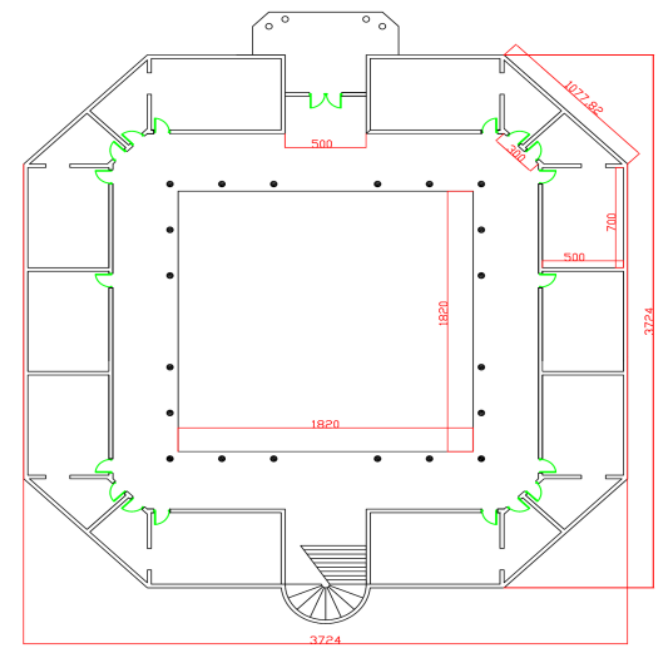

(a) Plan dimensioning

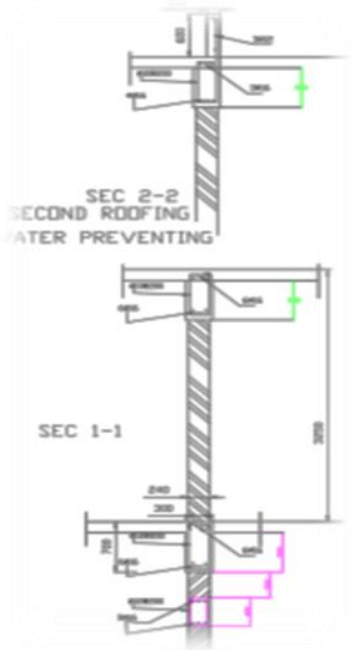

(c) Layout of brick wall

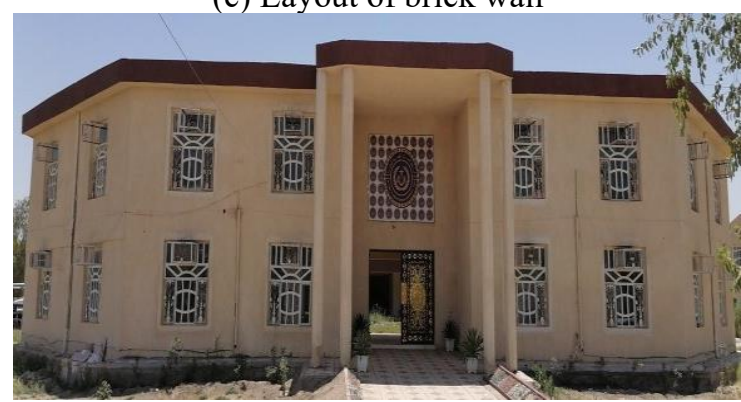

(e) Front view

\section{DESCRIPTION OF BUILDING LAYOUT AND CONSTRUCTION CASES}

The selected case study for the analysis is a laboratory building. It is a two-story building construction started at 2008 in the middle of Iraq (Babylon Government) from Al-Mussiab technical College buildings. The dimensions and detailing shown in Figure 1 where in general the building was $(37.25 \times 37.25 \mathrm{~m})$ with internal height of $3 \mathrm{~m}$ for each floor. The building is constructed from concrete system combined with bricks wall as shown in Figure 1. Most of the concrete columns are circler with $(30 \mathrm{~cm}$ in diameter) except the entrance columns where have a diameter of $40 \mathrm{~cm}$. All beams designed with dimensions depth $(50 \mathrm{~cm})$ with same brick wall width $(25 \mathrm{~cm})$

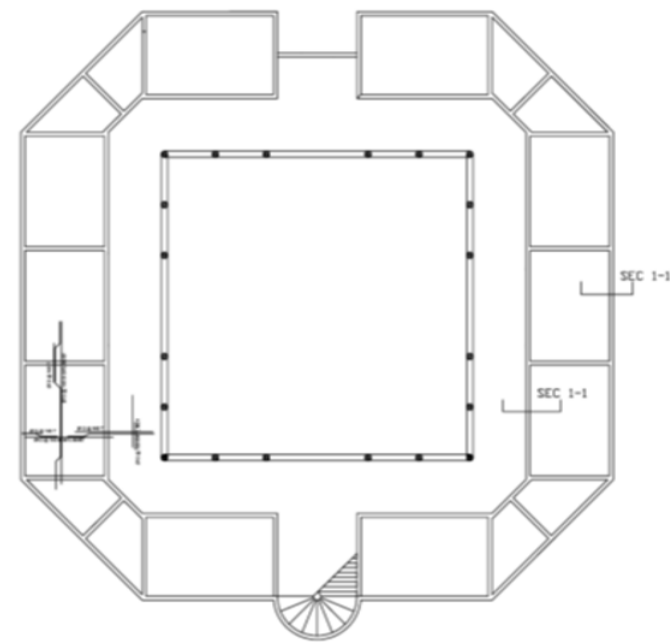

(b) Beams and columns system

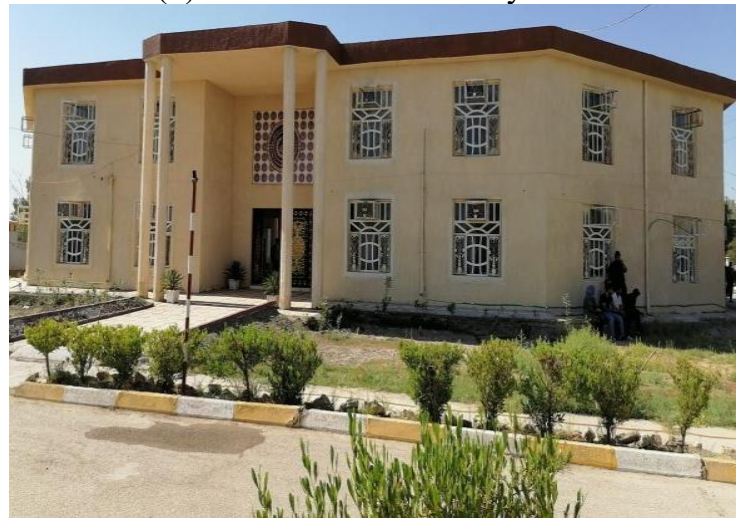

(d) Right side view

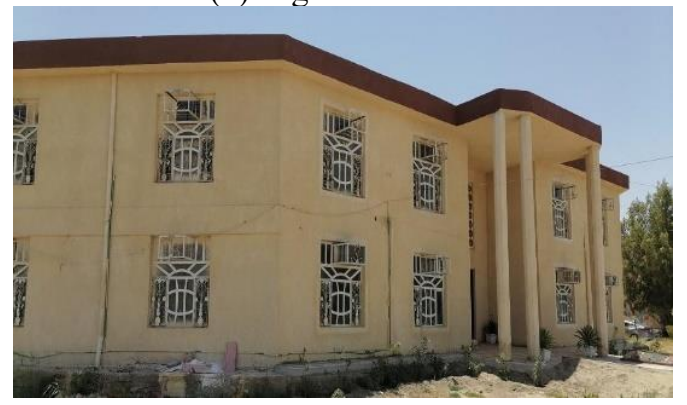

(f) Left side view

Figure 1. Building BX structure 
The researcher carries three cases of construction system, where in the first one the building is constructed from reinforced concrete frame system, and all walls considered non-bearing wall. The second case is a combination system, where the loading distributes to concrete frame system and bearing wall constructed from bricks, which is identical to the actual building. The second case is adopted herein in this study. The third case considers just bearing wall where all load transform to the foundation.

\section{NUMERICAL SIMULATION}

In this study, ANSYS software is used in the analysis of building. ANSYS is a finite element analysis, software, package, that play a very important role in structural design and analysis nowadays was used herein in this research study. There are two methods to apply the ANSYS applications through the graphical user interface (GUI), and through the use of batch file and ANSYS commands. Our research program is carried out using this application, where model prepared and considered to be the guidance for numerical solution.

\subsection{ANSYS re-processor}

The following processes steps are essentially for both linear and nonlinear analysis, even though a nonlinear analysis might consist of special elements and nonlinear material properties.

Model generation is conducted in this processor, which involves material definition, creation of a solid model, Specify element type. In the preprocessor (PREP7) contains the commands needed to build a model:

- Define element real constants.

- Define element types and options.

- Define material properties.

- Create model geometry.

- Mesh the object created.

- Model Operation.

The main function of FEA is to simulate numerically the behavior of a real construction system. In general, the analysis must be a precise numerical model of a physical sample. The model includes all the nodes, features, material properties, actual constants, boundary conditions and the other features that used to simulate the actual system. ANSYS proposes the following procedures to finish the generation:

a) Solid model creating

b) Adopting direct generation

c) Using a first model generated by computer-aided design system (CAD).

Herein in this study, there are two different methods used to create a model of building. These methods include solid model and direct generation. In solid modeling, the boundaries of the model will describe, controls establishment over the size and required shape elements automatically. On the opposite of that, in the direct generation method, it determines the location of every node and size, shape and connectivity of every element prior to defining these entities in ANSYS model. Solid modeling is generally more powerful and flexible than direct generation, and is commonly the preferred method for generation models.

The analysis kind must be described such as static analysis or dynamic analysis and it is used to find and evaluate of large deflection, large strain and large displacement, and then apply loads, specify load steps, and initiate the finite element solution. Non-linear analysis will be different from a linear solution in that it often requires load increments and always needs equilibrium iteration. In this study, applied a non-linear static analysis, with convergence criteria, then incremental load with specified load step will carried out, including special elements. The essential objective of this study is to check how a structure or component responds to definite loads situations by using the finite element technique. The loads include boundary conditions and externally or internally forces functions.

Analysis assessments stress, strain, reaction force, displacements, and the contact status. In this study analysis a new constructed building consists from concrete and bricks (deflections, minimum stress, maximum stress, cracks and crushing). The results reviewed by either general post processor (post 1) for contour plots at any time step or by timehistory post processor (post 26).

\subsection{Finite element modeling}

For determining and simulate the response of the structure or parts from it under specific type of loading, the finite element technique was selected and used. Linear response up to a certain limit of load was considered in typical loaddeflection behavior under monotonically loaded, then the nonlinearity starts after that. Where this non-linearity came from combination of material and geometric non-linearity, and interface nonlinearity for composite members. Herein in this study, geometric non-linearity due to large deformations was neglected. The governing equilibrium equations cannot be solved directly within the non-linear stage of behavior.

\subsection{Materials modeling}

Types of materials and its behavior used in the construction the members will for sure control its performance under any state of loading. While some members prepared of different materials (like concrete and bricks), where composite material constitute a composite system. In the same time, the composition of the used sub-material will affect its behavior, where concrete depend deeply on the properties of each of its components (cement mortar, aggregates and air voids). Then, such material considers with a totally varied inner structure. On the other hand, the brick dependent on the masonry material.

Concrete as state above is a material with a disgustingly varied inner structure. Concrete contains of aggregate elements surrounded by a bonding paste material which is made of cement and water. Chen clearly described the reality of bond micro-cracks at boundaries between the mortar and the coarse aggregate before the application of any load will consider as a basis of weakness in the structure of concrete. Thermal movements, shrinkage, and segregation in the mortar could cause many of these micro-cracks. Other reasons for developing micro-cracks were because of loading that effect directly the variance in stiffness among the aggregate and the plaster. Then, the non-linearity behavior of concrete will lead the regular growing of these micro-crack with additional loads. The nature and level of the induced stresses will control the behavior of concrete either to be linear or non-linear (less or more than allowable stresses).

In literatures, so many studies carry out an experimental program to check the performance of concrete under uniaxial and multi axial loading circumstances. Where, these studies 
focus on comprehend the intricate behavior of concrete for different required stress situations. All of that to offer an accurate numerical model that adopted by nonlinear finite element analysis to simulate the full structures constructed by concrete.

Clay bricks are readily available, mass-produced, thoroughly tested modular building components. Clay bricks are generally inexpensive, require almost no maintenance and have high durability and load bearing capacity. Finite element analysis of the failure procedure may be really valuable in these analyses. Constitutive model of the building material really required for conventional finite element analyses. Conversely, the preparation of closed-form constitutive relatives which can correctly define the aggregate dilapidation behavior of bricks is a difficult experiment. Figure 2 shows the building BX model by ANSYS.

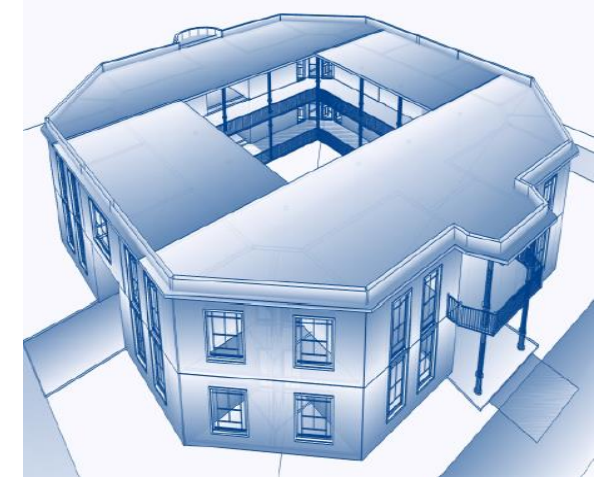

Figure 2. Building BX model by ANSYS

\section{NUMERICAL ANALYSIS OF COMBINED SYSTEM}

After checking the design of this building, they found that the total designed load was equal to $\left(15200 \mathrm{~N} / \mathrm{m}^{2}\right)$, while the deflection when distributed load applied was equal to $(0.979 \mathrm{~mm})$, while maximum stress was equal to $(0.165 \times 109$ $\left.\mathrm{N} / \mathrm{m}^{2}\right)$, minimum stress is equal to $\left(0.162 * 108 \mathrm{~N} / \mathrm{m}^{2}\right)$. At first stage of loading, no cracks were predicted or start to appear, where all members either concrete or brick behave in elastic reign. So No red points shown in the first stage of load. Building BX shows the first cracks at loading equal to (13500 $\mathrm{N} / \mathrm{m}^{2}$ ), where it was a minor small crack could be close if the loading removed as shown in Figure 3. These cracks start to appear in the outer beams over the opening of the windows because of this position is weaker part in building, therefore, it will be appeared small cracks under this amount of load.

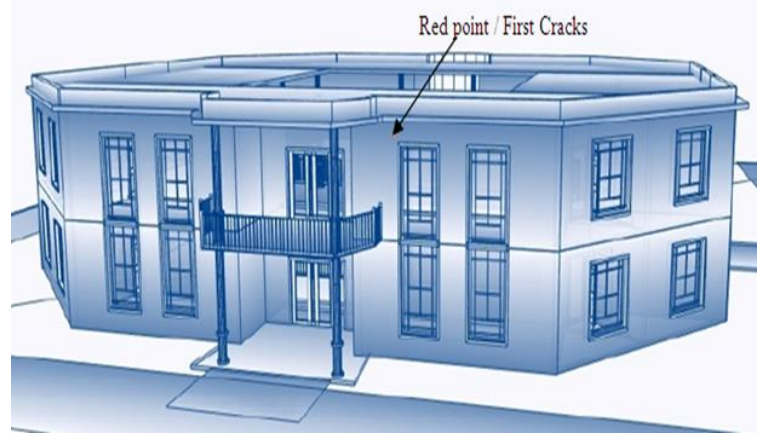

Figure 3. Building BX -first crack pattern at load (13500 $\mathrm{N} / \mathrm{m}^{2}$ ) carried out by ANSYS
Also, in the same position, the cracks appear at the stage of design load $\left(15200 \mathrm{~N} / \mathrm{m}^{2}\right)$, where all beam shows elastic behavior, except that location, where also a miner cracks lighting with red color as shown in Figure 4. That lead the researcher to stop loading and start unloading operation, to check if that will be fixed or not. Actually, the numerical program carried by ANSYS fix the satiation of this point mention to its still effective point and still can carry load as other within an elastic behavior.

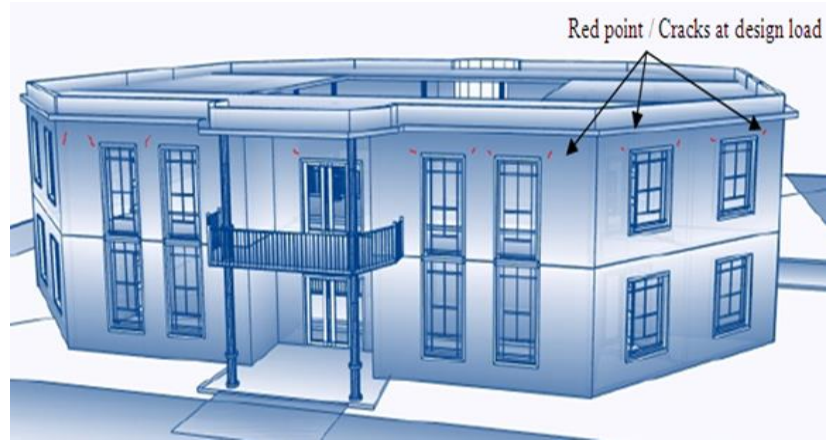

Figure 4. Building BX - cracks pattern at distributed load $\left(15200 \mathrm{~N} / \mathrm{m}^{2}\right)$ carried out by ANSYS

Cracks start to increase by increasing loading within several steps up to the maximum ultimate distributed load equal to $\left(40000 \mathrm{~N} / \mathrm{m}^{2}\right)$, Figure 5 shows the cracks distribution at last loading stage. The cracks separate overall the concrete system (Beam/Column) and also appear in the slab in different location. Both concrete and brick shows cracks, especially near to the point of stress concentration around the opening of doors and windows.

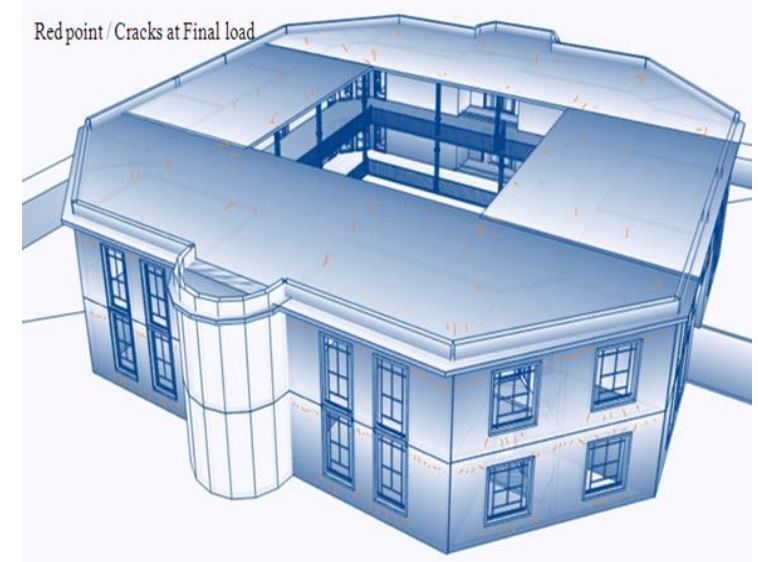

Figure 5. Building BX - cracks pattern at distributed designed load $(40000 \mathrm{~N} / \mathrm{m} 2)$ carried out by ANSYS

\section{ANALYSIS RESULTS}

Sudden cracks of concrete are a systematic cause of grievances. Drying shrinkage, thermal contraction, restraint to shortening, subgrade settlement, and applied loads were the most common causes for cracking in concrete, either from one of them, or a combination. Cracks can be considerably decreased when the causes are considered and preventive stages are employed. Herein in this study, the numerical and site investigations are focus on the cracks obtained from applied load. Conventional loading stages are applied and 
cracks monitored either by the numerical model or in site checking. Material nonlinearity was the main subject that predict the cracking overall structural members, where that will appear clearly in the numerical analysis. In the present study, the sources of material nonlinearity are cracking of concrete, deformation of concrete and bricks, crushing of concrete and bricks. Where, the main objective of this study is to examine the structural behavior of buildings strengthened in flexural.

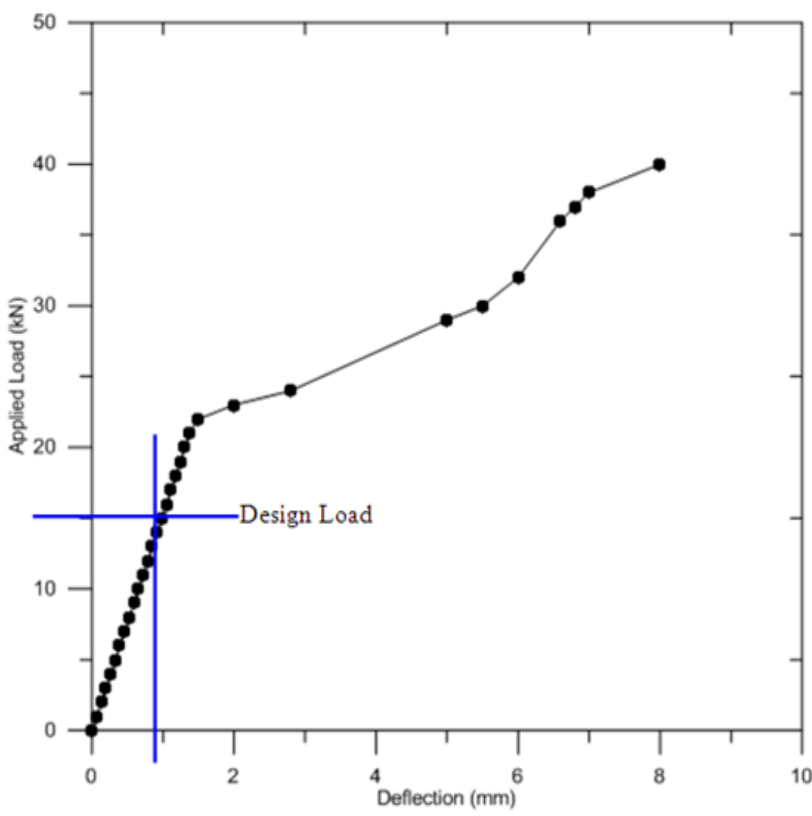

Figure 6. Building BX - internal beam Load - deflection curve

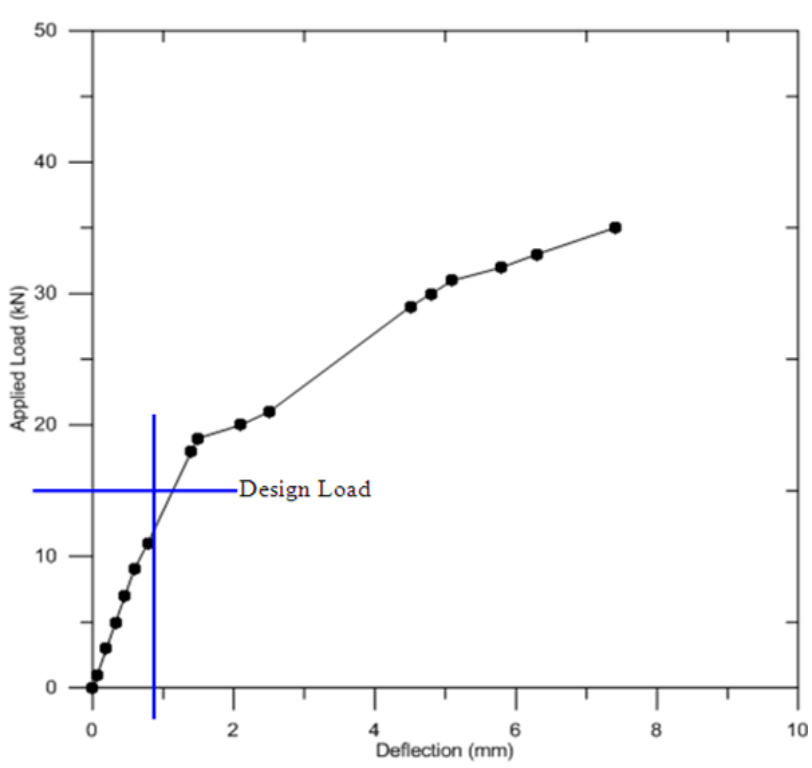

Figure 7. Building BX -external beam Load - deflection curve

Figure 6 shows the resulting load-deflection curve for lateral internal beam, where it considers the most critical beam with maximum loading state. Clearly shown that the design load was within the elastic region within factor of safety about 1.5 , where the design load is about $67 \%$ from the cracking stage. The ultimate loading reach about $260 \%$ from the design load, and the total deflection will not be more than $8 \mathrm{~mm}$.
Which mean that the beam shows rigid behavior than to be more flexible. Repaid increase with deflection occurs after cracking start at loading about 146\% from the design load, where the deflection doubled at few steps of loading increments.

Figure 7 shows the load-deflection curve for the critical external rounded beam, where it appears how it has been less effected by the applied load and its shows more flexible behavior.

\section{STRESS CONCENTRATED FACTOR}

Herein the stress concentrated factor for wall only could be calculated from formula:

$$
K t=\frac{\sigma M a x .}{\sigma N o r m a l}
$$

where:

$\sigma$ Max. $=$ maximum stress from ANSYS program

$\sigma$ Normal $=$ normal stress equal to Force $/$ Area

Force $=$ concentrated load $=$ distributed load $/$ area of wall consisted of doors or windows.

Area $=$ area of wall consisted of doors or windows.

The values of variation of stress concentration factor can be shown in Figure 8.

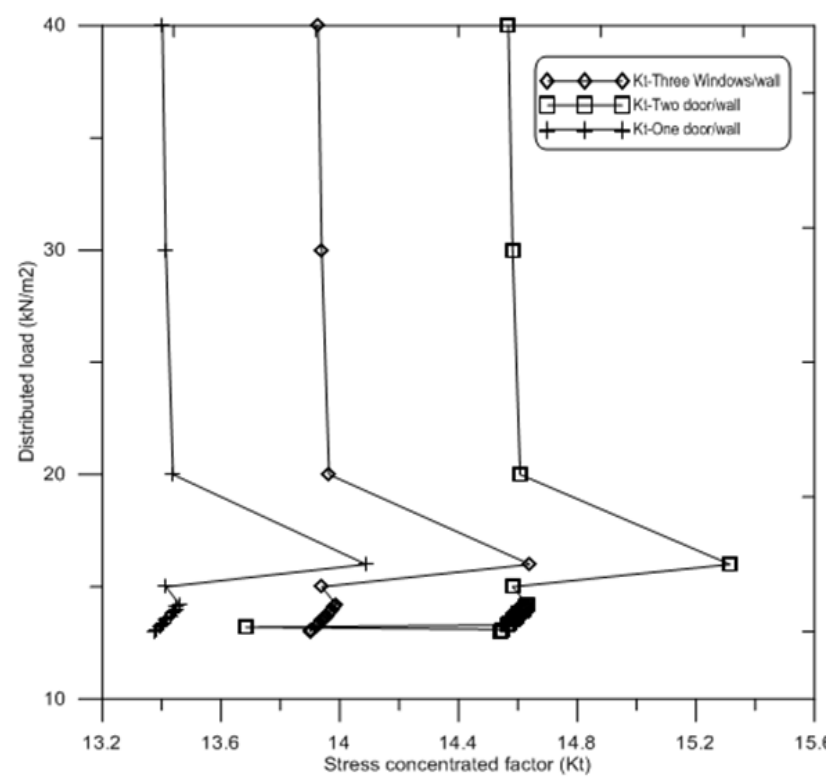

Figure 8. Building BX - variation of Kt factor

\section{EXPERIMENTAL INVESTIGATION OF CRACKS}

Figure 9 shows the microscope tool which is used to measure the cracks width in concrete. The used microscope is additional improved by having its own modifiable light foundation for dark environments. The appearance is concentrated by rotating a knurled handle on the side of the tool, and the eyepiece gauge can be rotated through 360 degrees to bring into line with the direction of the crack, pitch, under investigation. The lower scale of measurement is $4 \mathrm{~mm}$ for crack width, and it divided into $0.2 \mathrm{~mm}$ partitions, which are subdivided into $0.02 \mathrm{~mm}$ partitions. Accepted codes of repetition, revels that calculated higher crack widths must not 
exceed definite values which are presented in BS 8110 standard (Part 2) for concrete. This standard allows crack width is equal to $0.3 \mathrm{~mm}$ which is 15 partitions on the gauge for most types of situations.

The research plan in the site is focus on the looking for any cracks appear or start to appear. That is done by considering a survey questionnaire to the owner of the building and to the engineer whom responsible of its construction and maintenance. All defect is recorded at the first day of inspection and take about six months investigation. All cracks that recorded at the initial time are tested and measured to sort its data and check the variation along these periods. In general, constant values are notified.

Figures 10-12 show the processing of recording cracks and monitoring. Almost the cracks appear in the brick walls, where the opening founded specially under windows where concentration of stresses are there. Beam cracking is invisible, and the site investigation couldn't record any at all time of checking and recording. That is because the building isn't loaded that much, when calculating the applied load found its almost $55 \%$ from the design loading. So it's early to find cracking on beams or slab.

Good roofing type and working, keep the structure prevented from the effect of the environmental effect that done

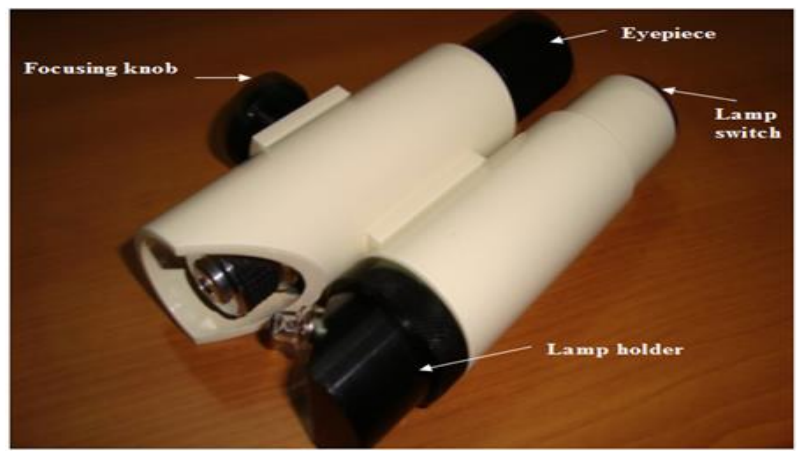

(a) Microscope tool by leakage of rainwater to the slab or beam, which in its role might reduce the strength resistance of these members, that will appear in cracking.

Table 1 shows the results of the site investigation which are presented by cracks width and length measurements during the first six months. All data recorded shows constant values and stability of building. Actually, with no increasing of loading, the building reach its stable state, and defect will not develop. That basically because of good design within conventional state of loading. Figure 13 shows the history of cracks width variation within the recoding period.

Table 1. Building BX - cracks width and length measurement

\begin{tabular}{ccccc}
\hline Time (day) & \multicolumn{4}{c}{ Crack width (mm) } \\
& A & B & C & D \\
\hline 1 & 0.065 & 0.09 & 0.145 & 0.080 \\
30 & 0.070 & 0.09 & 0.150 & 0.085 \\
60 & 0.075 & 0.09 & 0.155 & \\
90 & 0.075 & 0.09 & 0.160 & 0.085 \\
120 & 0.075 & 0.09 & 0.160 & \\
180 & 0.075 & 0.09 & 0.160 & 0.085 \\
Crack Length & $18 \mathrm{~cm}$ & $125 \mathrm{~cm}$ & $25 \mathrm{~cm}$ & $18 \mathrm{~cm}$ \\
\hline
\end{tabular}

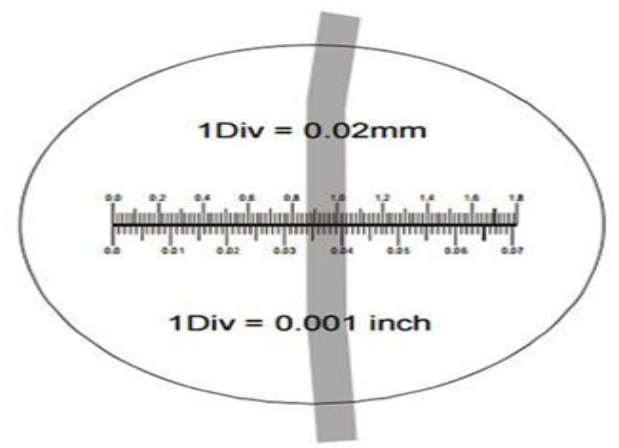

(b) Divisions of measured rule

Figure 9. Microscope used to monitor the cracks propagation

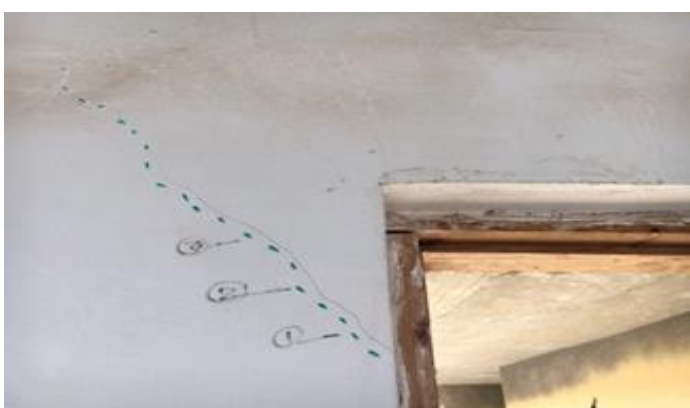

(a) Crack near door No.1

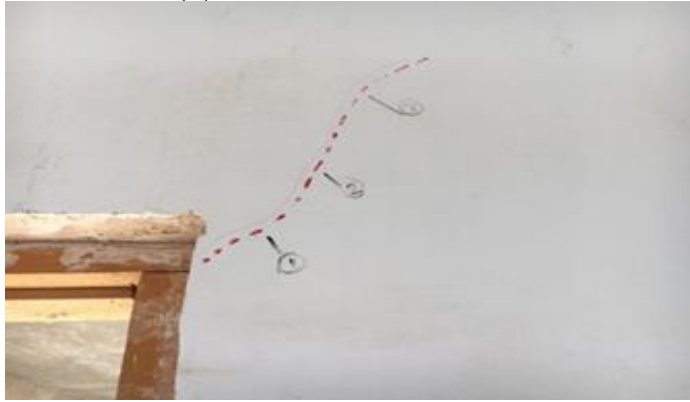

(c) Crack near door No.3

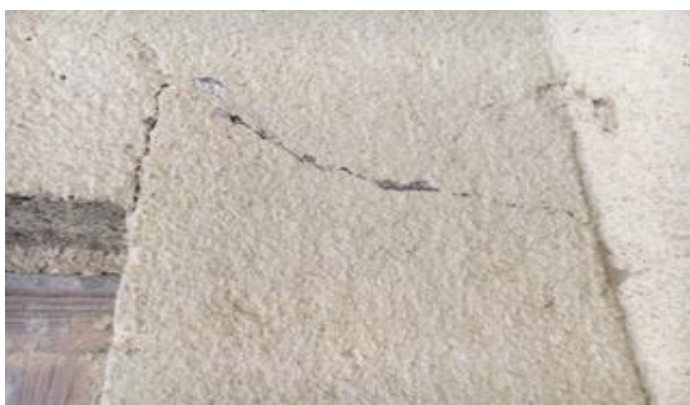

(b) Crack near door No.2

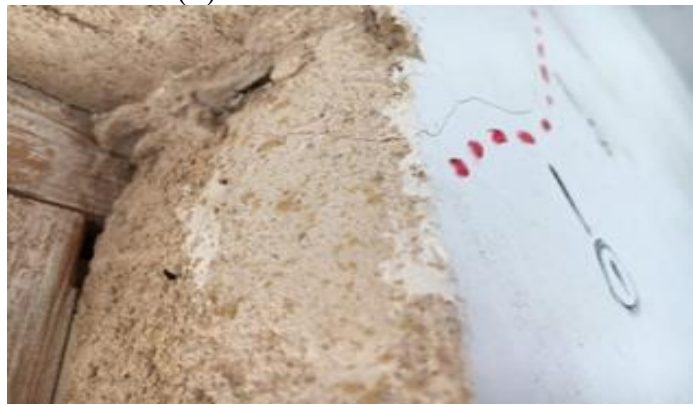

(d) Crack near door No.4

Figure 10. Building BX - cracks recording and monitoring around doors 


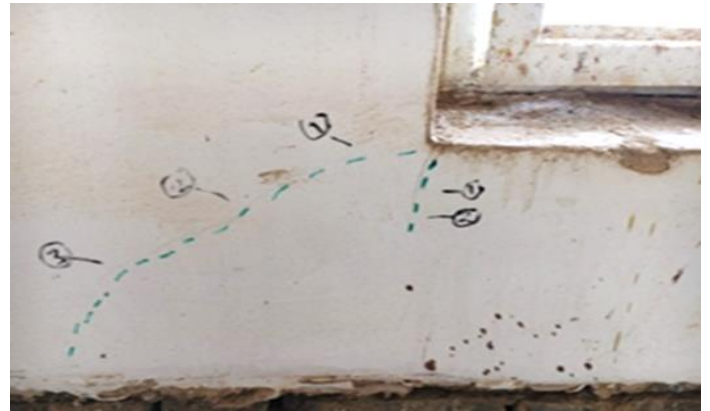

(a) Crack near window No.1

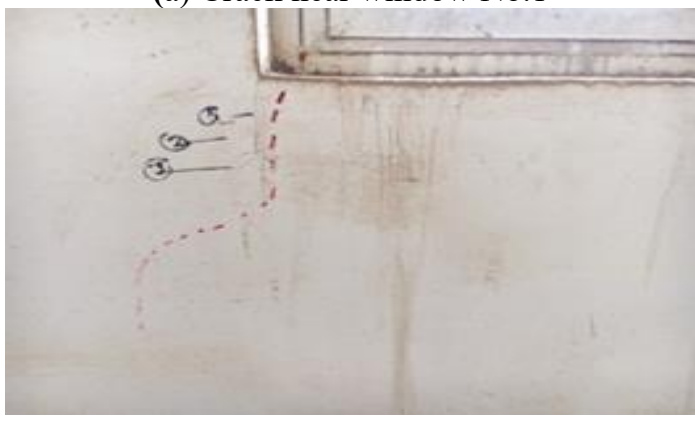

(c) Crack near window No.3

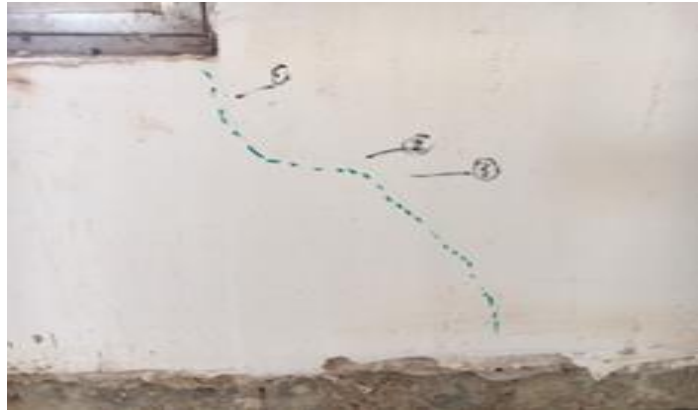

(b) Crack near window No.2

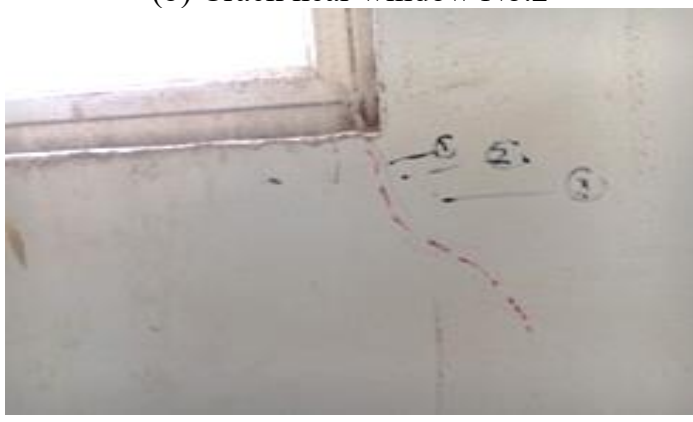

(d) Crack near window No.4

Figure 11. Building BX - cracks recording and monitoring around windows

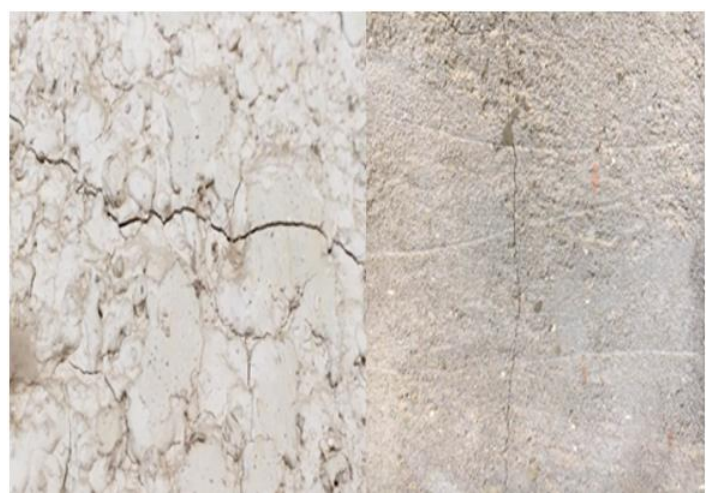

Figure 12. Building BX - cracks recording and monitoring on walls

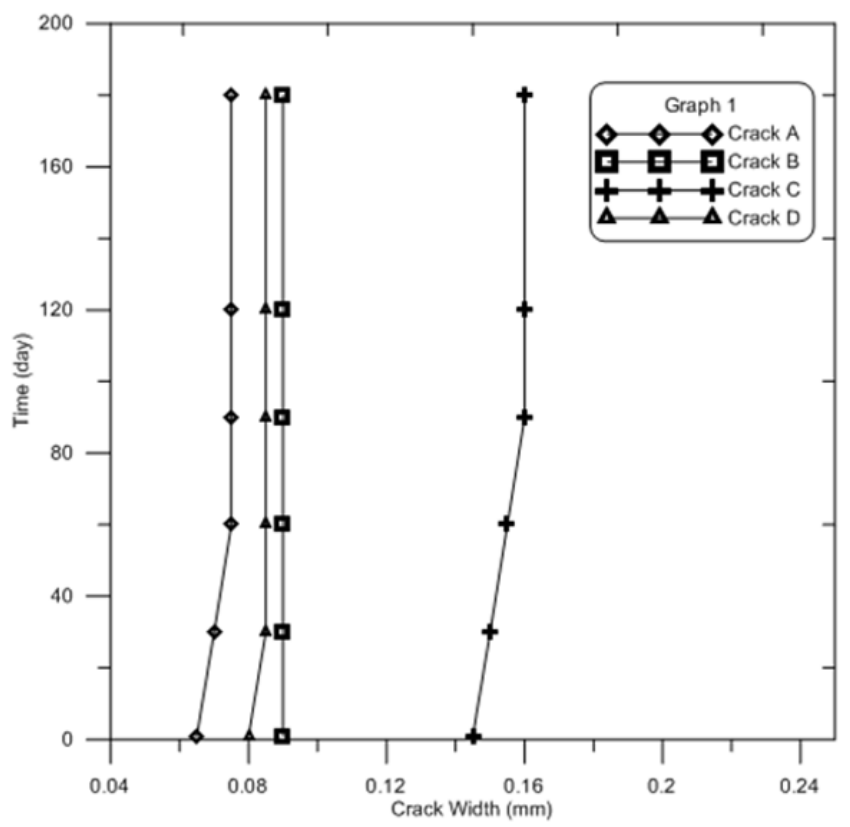

Figure 13. Building BX- time history for crack width extend

\section{CONCLUSIONS}

The conclusions of this study are:

(1) The goal of this study was to gain a numerical model and prove its compatibility to the actual structure, so all design could be checked and all defect must be prevented. This study works adopted a powerful technique which it was the finite element method to simulate the behavior of full constructed building with both concrete system and brick bearing wall. Where the adopted numerical procedure allows to the users to predict the response of building elements due to conventional state of loading.

(2) The prediction of full responses and behavior of each element and their connection showed the precise of factor of safety used by the designer, where the analysis prove that the design load was about $67 \%$ from the cracking load, and the ultimate load was about $260 \%$ from the design load. That will allow more sustainability and stability for long time deformation.

(3) In the analysis by the finite element method, generally, repaid increase with deflection occurs after cracking start at loading about $146 \%$ from the design load, where the deflection doubled at few steps of loading increments.

(4) Site investigation shows that all data recorded was constant values and the building was stable. Actually, with no increasing of loading, the building reach its stable state, and defect will not develop. That basically because of good design within conventional state of loading

(5) The final conclusion is that the finite element model gives an accurate procedure to simulate the building that have been proved by site investigate through show matching with its result. Even that the model can show the full behavior up to the failure at the ultimate state of loading.

\section{REFERENCES}

[1] Yiping, Z., Sálvano, B., Jochem, L. (2004). Good building design and construction. Handbook on Good 
Building Design and Construction in the Philippines, Makati City Metro Manila, Philippines.

[2] Alaaraji, R.M., Kashmola, S.Y. (2020). Evaluation of damage index for RC frames with irregular geometrical shape subjected to blast loads. Tikrit Journal of Engineering $\quad$ Sciences, 27(2): 54-64. http://dx.doi.org/10.25130/tjes.27.2.07

[3] Ali, N. (2016). Building structural systems, concrete design lectures, Fourth Year, Civil Engineering Department, Al-Kufa University.

[4] Umar, M., Faslih, A., Arsyad, M., Sjamsu, A., Kadir, I. (2017). Building structure housing: Case study of community housing in Kendari city. IOP Conf. Series: Materials Science and Engineering, 267: 012025. http://doi.org/10.1088/1757-899X/267/1/012025

[5] Olli, I. (2014). Building construction. AMK University of Applied Sciences.

[6] Luković, M., Hordijk, D.A., Huang, Z., Schlangen, E. (2019). Strain Hardening Cementitious Composite (SHCC) for crack width control in reinforced concrete beams. Heron, 64(1/2): 189-206.

[7] Lacarriere, L., Sellier, A., Souyris, P., Kolani, B., Chhun, P. (2020). Numerical prediction of cracking risk of reinforced concrete structures at early age. RILEM Technical Letters, 5: 41-55. https://doi.org/10.21809/rilemtechlett.2020.106

[8] Schlicke, D., Dorfmann, E.M., Fehling, E., Tue, N.V. (2021). Calculation of maximum crack width for practical design of reinforced concrete. Civil Engineering Design, 3(3): 45-61. https://doi.org/10.1002/cend.202100004

[9] Leonhardt, F. (1988). Cracks and crack control in concrete structures. PCI Journal, 33(4): 124-145. https://doi.org/10.15554/pcij.07011988.124.145

[10] Beeby, A.W. (1978). Corrosion of reinforcing steel in concrete and its relation to cracking. Structural Engineer, 56(3): 77-81.

[11] EN1992-3. (2006). EC2-design of concrete structures Part 3 Liquid retaining and containment structures.

[12] Janusz, R., Piotr, K. (2017). Evaluation aspects of building structures reconstructed after a failure or catastrophe. IOP Conf. Series: Materials Science and Engineering, 245: 032099. https://doi.org/10.1088/1757899X/245/3/032099

[13] Krentowski, J. (2015). Disaster of an industrial hall caused by an explosion of wood dust and fire. Engineering Failure Analysis, 56: 403-411. https://doi.org/10.1016/j.engfailanal.2014.12.015

[14] Docevska, M., Arangjelovski, T., Markovski, G., Nakov, D. (2018). Numerical and analytical model for serviceability limit states of RC elements. Građevinar, 70(11): 943-952. https://doi.org/10.14256/JCE.2050.2017
[15] Gilbert, R.I. (2008). Calculation of long-term deflection. In CIA Seminar - Control of Long-Term Deflection Brisbane (Vol. 23).

[16] Mahmood, N.K., Lateef, A.M. (2021). Effect of corrosion longitudinal steel bars on the flexural strength of RC beams. Tikrit Journal of Engineering Sciences, 28(2): 44-53. http://doi.org/10.25130/tjes.28.2.04

[17] Naga, K., Lingeshwaran, N. (2017). Analysis and design of $\mathrm{G}+5$ residential building by using E-TABS. International Journal of Civil Engineering and Technology, 8(4): 2098-2103.

[18] Krishna, V., Chandrashekar, R. (2015). Analysis and design of multi storied building by using ETABS software. Vardhaman College of Engineering Hyderbad, 4(7): 551-552.

[19] Balaji, U.A. Selvarasan, M.E.B. (2016). Design and analysis of multi-storeyed building under static and dynamic loading conditions using ETABS. International Journal of Technical Research and Applications, 4(4): 15.

[20] Reddy, S.V.B., Madhu, V. (2018). Comparative study on design results of a multi-storied building using STAAD PRO and ETABS for regular and irregular plan configuration. International Journal of Applied Engineering Research, 13(15): 12194-12201.

[21] Ozer, H.O., Hacioglu, Y., Yagiz, N. (2017). Controlling the building model using high order sliding mode control optimized by multi objective genetic algorithm. Periodicals of Engineering and Natural Sciences (PEN), 5(3): 256-262. https://doi.org/10.21533/pen.v5i3.91

[22] Baisbay, T., Berik, M., Yairakhan, B., Zhenisbek, A., Zhenis, I.A. Aldiyarov, A. (2019). Seismic resistance of multi-storey reinforced concrete wall-frame structures at destructive earthquakes. Periodicals of Engineering and Natural Sciences, 7(4): 1582-1598. http://doi.org/10.21533/pen.v7i4.841.g427

[23] Pina, U. (2019). Sustainability of traditional buildings located in rural area. Periodicals of Engineering and Natural Sciences, 5(2): 231-236. http://doi.org/10.21533/pen.v5i2.136

[24] Chandrakala, V., Bindu, K., Chethan, R., Pramod, S., Sharath, M. (2018). Analysis and design of G+4 commercial building using ETABS. International Journal of Scientific Development and Research, 3(6): 381-387.

[25] Nagaratna, S., Ranjita, N., Asif, R., Vijaykumar, K., Sudha, P., Maganur, D. (2019). Analysis and design of multistorey building $(\mathrm{G}+3)$ by using ETABS software. International Research Journal of Engineering and Technology, 6(5): 5570-5576.

[26] Mahmood A.M., Mohammad K.I. (2019). Finite element analysis for RC deep beams under an eccentric load. Tikrit Journal of Engineering Sciences, 26(1): 41-50. http://doi.org/10.25130/tjes.26.1.06 